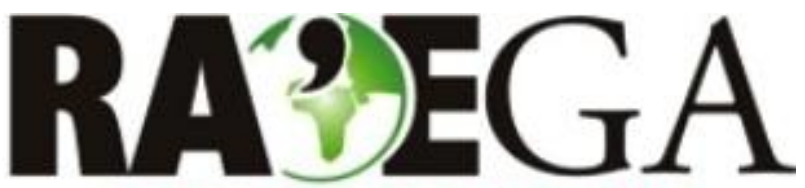

O ESPACO GEOGRÁFICO EM ANÁLISE

\title{
A PRAÇA, A POÉTICA E OS PROCESSOS DE IDENTIDADE: DESVELANDO ASPECTOS DA IDENTIDADE URBANA
}

\section{THE SQUARE, THE POETICS AND THE IDENTITY PROCESSES: UNVEILING ASPECTS OF URBAN IDENTITY}

\author{
Tomas Mambo Seda Francisco \\ Graduando em Psicologia \\ Universidade do Extremo Sul Catarinense (UNESC) \\ Criciúma, SC \\ e-mail:mamboseda@hotmail.com \\ José Ivo Follmann \\ Professor da Universidade do Vale do Rio dos Sinos \\ Unidade Acadêmica de Pesquisa e Pós Graduação \\ São Leopoldo, RS \\ e-mail: jifmann@hotmail.com \\ Eduardo Nogueira Giovanni \\ Professor da Universidade do Extremo Sul Catarinense (UNESC) \\ Departamento de Arquitetura e Urbanismo \\ Criciúma, SC \\ e-mail: dugiovanni@unesc.net \\ Teresinha Maria Gonçalves \\ Professor da Universidade do Extremo Sul Catarinense (UNESC) \\ Laboratório de Pesquisa sobre Meio Ambiente, Desenvolvimento Urbano e Psicologias Ambientais \\ Criciúma, SC \\ e-mail: tmg@unesc.net
}

\section{Recebido em: 02/01/2013}

Aceito em: 20/02/2014

\section{Resumo}

A identidade urbana ou os processos urbanos de identidade são abordados por meio da reflexão sobre a vida social numa praça. A Praça Nereu Ramos, situada em Criciúma-SC, não é o objeto deste estudo, mas é o pretexto de uma ampla discussão sobre como os seus usuários ativos e passivos se relacionam com ela e nela. Com a distinção entre espaço e lugar, o estudo aborda o conceito de lugar antropológico e aponta para importantes pistas sobre a praça como lugar incubador 
de processos de identidade. É o que faz com que um simples espaço se transforme em um lugar pleno de conteúdos simbólicos. Essa passagem da "condição" de espaço para a "condição" de lugar é resultante da fecundação das funcionalidades frias, calculadas e inóspitas - pela "habitação" do ser humano com sua poética e seus processos de identidade repletos de pulsações e de vida. A praça não é mais espaço de conveniências e funcionalidades, mas lugar de vida, de memória, de saudade e de cultivo pessoal. .A metodologia utilizada foi composta pelas técnicas de observação sistemática e técnica do GAMOC, as quais foram praticadas durante um ano (07/2011-07/1012) e serão explicitadas no interior do texto. As observações foram anotadas no diário de campo e analisadas à luz dos aportes teóricos aqui apresentados.

Palavras-chave: Praça; Poética Urbana; Processos de Identidade; Lugar Antropológico; Identidade de Lugar.

\begin{abstract}
The urban identity ore the urban processes of identity are addressed through a reflection on the social life in a square. The Nereu Ramos plaza, Criciúma, SC, Brasil is not the object of study, but it is the pretext for a broad discussion on how their assets and liabilities users relate to it and in it. With the distinction between space and place, the study discusses the concept of anthropological place and points to important clues about the square as incubator of a place of identity processes. It's what makes that a simple space becomes a place full of symbolic content. This change between the "condition" of space for the "condition" of place, is the result of the fertilization of the cold, calculated and inhospitable functions of the "housing" of the human being, with his poetics and his replete of pulses and life identity processes. The square are no more convenience and functionality spaces, now are places of life, of memory, of nostalgia and personal gardening The methodology used, consisted of observation techniques and the systematic observation, GAMOC, techniques that are explained within the text, methods that were practiced for one year (07/2011-07/1012). The observations were recorded in the field diary and analyzed under the spotlight of the theoretical framework presented in this document.
\end{abstract}

Keywords: Square; Urban Poetics; Identity Processes; Anthropological Place; Place Identity.

\title{
INTRODUÇÃO
}

Nas observações que os estudiosos fazem sobre as realidades urbanas e os processos nelas envolvidos, as suas praças (e a vida que as anima), apesar de em muitos contextos e por diferentes motivos estarem relegadas a segundo plano, podem ser consideradas como espaços privilegiados de encontros que se entrecruzam. 
As perspectivas de praça como espaço público, apropriação do espaço, processos de identidade, poética e identidade urbana, lugar antropológico e identidade de lugar constituem-se os principais veiculadores das reflexões e das argumentações deste artigo, que dá conta de um encontro transdisciplinar entre sensibilidades da psicologia ambiental, da arquitetura, da geografia e da sociologia e também de sensibilidades do observador comum. Pode parecer estranho, em tempos em que os shoppings e outros espaços mais preservados e sofisticados se tornam as alternativas mais procuradas, que se possa ainda dar atenção à importância e à função da praça. O estranhamento faz-se, no entanto, necessário enquanto puder ajudar a veicular uma proposta de recuperação e afirmação de sensibilidades humanas e ambientais, das quais a sociedade tende a carecer sempre mais. Mesmo cientes das limitações que a tarefa nos impõe, mas mediante uma reflexão construída a partir da observação de quem, no meio do burburinho artificial e poluído da vida urbana, consegue deixar-se habitar pela poética fruída na relação com a natureza verdejante de uma praça, deseja-se, ao longo destas páginas, propor uma revisita, ainda que despretensiosa, a esse lugar antropológico.

\section{MATERIAL E MÉTODOS}

A Praça Nereu Ramos, situada na cidade de Criciúma ${ }^{1}$, sua localização histórica, física, geográfica, social e seus conteúdos simbólicos são o cenário de referência do estudo aqui apresentado. Não se trata de um estudo sobre referida praça, mas esta é o seu pretexto. Trata-se de uma visita à praça como um lugar profundamente antropológico conforme figura 1 que segue. $O$ estudo quer ser uma pequena contribuição à discussão mais ampla que o Grupo Interdisciplinar e Interinstitucional de Estudos e Pesquisas sobre Meio Ambiente e Espaço Urbano Gipmaur vem realizando, na sua busca por avançar no entendimento do conceito de identidade urbana ou de processos urbanos de identidade e do conceito de identidade de lugar.

${ }^{1}$ Criciúma é uma cidade do estado de Santa Catarina, situada na região sul do Brasil. Foi considerada, por um longo período, como a capital da indústria da extração do carvão no País. 


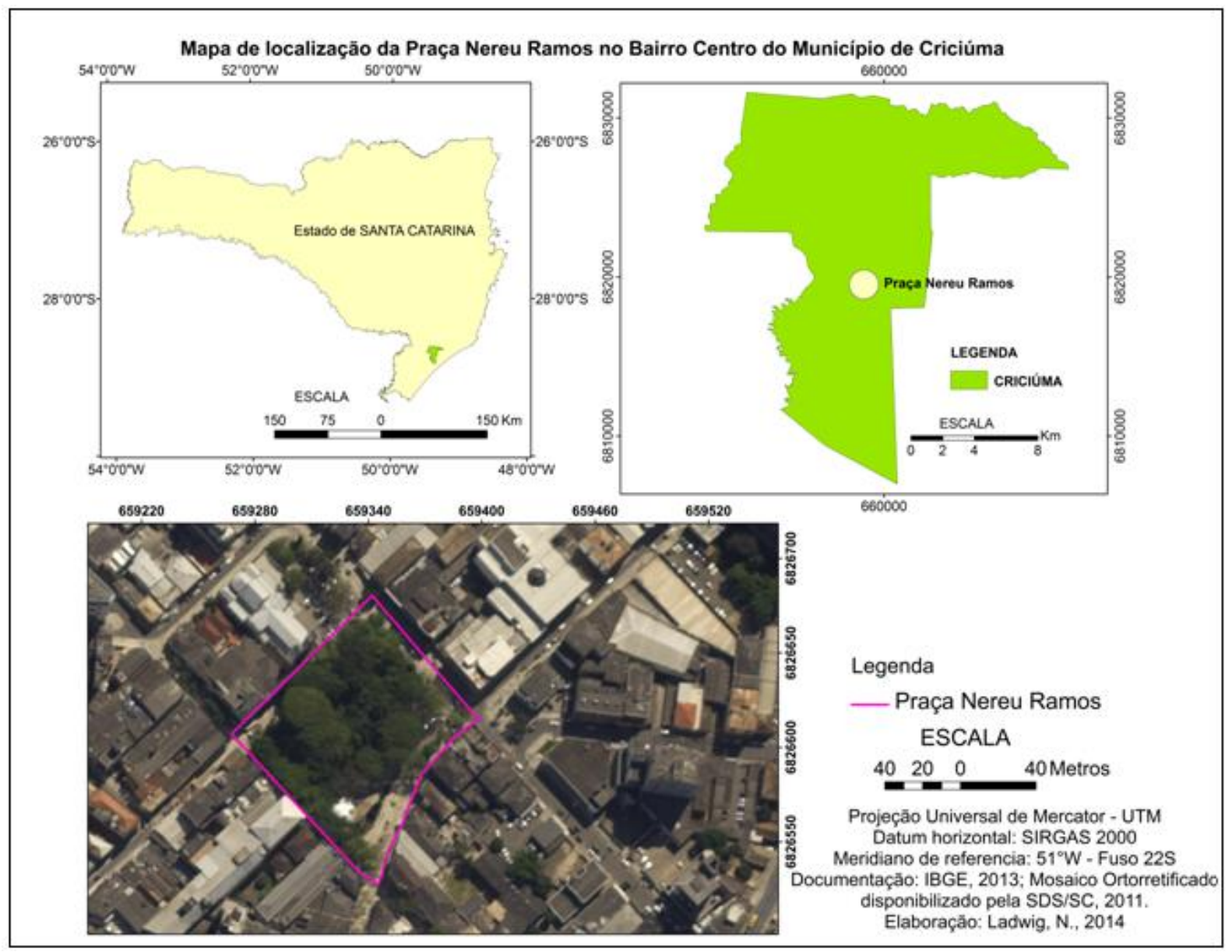

Figura 1: Localização da área de estudo

Fonte: Ladwig (2013)

A par das informações históricas relativas à constituição da praça nessa cidade, extraídas de documentos oficiais locais, de sítios eletrônicos ou de autores familiares e conhecidos e de algumas referências teóricas chaves, o estudo está baseado, principalmente, em observação participante direta na vida cotidiana da Praça Nereu Ramos - daqueles que "habitam" de diferentes formas este lugar antropológico. Alimentamos a mesma perspectiva do autor que escreveu que 0 método observacional é "um dos métodos mais utilizados em ciências sociais e que apresenta alguns aspectos curiosos [...] Possibilita o mais elevado grau de precisão nas ciências sociais" (GIL, 1989, p. 34). A partir de incursões leves e discretas, como as de um "gato"; de olhares penetrantes e agudos, como os da "águia"; de percepções para além da visão, como as de um "morcego" e do bom faro, como o de um "cão", as observações que conseguimos formular são para nós, se não totalmente novas, no mínimo sugestivas e portadoras de intuições mobilizadoras. $O$ 
artigo também quer fazer uma homenagem a um conjunto de técnicas de observação agrupadas sob a sigla GAMOC, sigla esta composta das iniciais dos animais aqui referidos. ${ }^{2}$

A metodologia, como a analogia dos animais quer mostrar, consistiu na presença observadora dos pesquisadores ao mesmo tempo discreta (leve), penetrante, aguda, perspicaz e seletiva. Foram muitas horas de presença na Praça Nereu Ramos, que neste texto dialogam com os diferentes autores, os quais constituem o horizonte teórico do estudo.

\section{RESULTADOS E DISCUSSÃO}

\section{BANHADÃO CORTADO POR UM PEQUENO RIO}

Existem muitos registros da história de Criciúma. Foi escolhida como referência paradigmática uma passagem do texto de Naspolini, no qual ele se expressa da seguinte forma: "[...] aos poucos foi iniciada a urbanização do centro, daquele banhadão que era cortado por um pequeno rio. Nas margens desse rio que é Rio Criciúma - foram construídas algumas casas e a colônia foi tomando jeito. E foi correndo". (NASPOLINI, 2007, p. 37).

A referência ao banhadão cortado por um pequeno rio, além da força descritiva, revela também uma fruição poética, pois esse banhadão e este pequeno rio, ao longo da história, foram "correndo" e tomando formas.

A poética transporta o ser humano para além do seu espaço e tempo. Ou, melhor, refaz o espaço e o tempo, transcendendo-os. A poética é uma dimensão inerente e comum a todos os seres humanos em que a pessoa transcende a própria história e o próprio momento vivido em um espaço dado (GONÇALVES, 2007, p. 39).

O "banhadão cortado pelo rio" é uma expressão de certa forma grotesca, mas que suporta dentro dela importantes fruições poéticas para os moradores da poluída e agitada cidade de Criciúma ou, especificamente, para os frequentadores da Praça Nereu Ramos, que é a referência e pretexto empíricos deste estudo.

\footnotetext{
${ }^{2}$ Gamoc é uma técnica utilizada pelos pesquisadores de campo, na qual estes fazem uso das características mais expressivas dos animais com as iniciais do conceito (Gato, Águia, Morcego, Cão) concebido por Gonçalves (2004).
} 


\section{CONSTITUIÇÃO DA POPULAÇÃO (POVOAMENTO MEDIANTE AFLUXO DE GRUPOS DIVERSOS)}

Criciúma recebeu os primeiros colonizadores em $1880^{3}$. Trata-se de um ano marco, data memorável. Assistiu-se, a partir daquele momento, uma sequência de afluxo populacional por meio de diferentes etnias que constituíram o que hoje é a população de Criciúma em termos culturais e étnicos.

No período de 1880 a 1910, houve afluxo de grupos de pessoas integrados por italianos, alemães (germânicos), poloneses, portugueses (lusos) e afrodescendentes. Todos afluíram em momentos diferentes ao longo desse período.

No bojo desse fenômeno migratório e em decorrência do mesmo, formou-se também o processo de distanciamentos humanos e desigualdades sociais entre as diversas identificações culturais dentro do mesmo mosaico cultural. Tal processo, diga-se de passagem, não deve ser considerado um empobrecimento da cultura local, e sim, apesar dos efeitos perversos do distanciamento e da desigualdade, a afirmação de sua riqueza pela diversidade cultural.

A intenção aqui não é a de dar conta de todo o processo de constituição da cidade e sua diversificação que aconteceu, sobretudo, ao longo do século XX, mas sim referir o principal núcleo originário para circunscrever a área inicial, aquela onde hoje se encontra a Praça Nereu Ramos.

\section{A HISTÓRIA DA PRAÇA (DE UM ESPAÇO FÍSICO ÚTIL PARA UM LUGAR ANTROPOLÓGICO)}

No ano de $1913^{4}$, a cidade conheceu o que seria a grande alavanca que mudaria toda a sua história, quer em nível econômico, estrutural e urbanístico, quer cultural. Foi a descoberta e identificação da primeira mina para exploração do carvão. Naquela época, ainda não existia, enquanto tal, o que hoje é a Praça Nereu Ramos, mas esta já se constituía como um espaço identificado para tal finalidade (a

\footnotetext{
3“A data de 6 de janeiro de 1880 é considerada como aquela da fundação e início da colonização do município, com a chegada das primeiras famílias de italianos provenientes da região do Vêneto, norte da Itália. Eram um total de 22 famílias, que somavam 141 pessoas." (CRICIÚMA, 2012).

4"Em 1913, tem início o ciclo do carvão, com a descoberta das primeiras jazidas do minério. Este fato foi o grande propulsor do desenvolvimento econômico do município, gerando empregos e atraindo investimentos, tendo seu auge entre as décadas de 1940 a 1970. Durante este período, Criciúma ficou conhecida como a "Capital Brasileira do Carvão". (CRICIÚMA, 2012). "Em 1917 entra em operação a Companhia Brasileira Carbonífera Araranguá (CBCA)”. (HISTÓRICO..., 2012).
} 
de espaço público). Tratava-se de um local onde se colhia alimentos para os animais, um largo cheio de coqueiros e palanques nos quais os italianos, quando vinham ao centro, amarravam seus cavalos e estacionavam suas "aranhas" ${ }^{5}$, carros de boi e carroças (NASPOLINI, 2007, p. 193).

A criação da Praça se deu em 1917. Coincidentemente, naquele ano entrou em ação a Companhia Brasileira Carbonífera Araranguá $(\mathrm{CBCA})^{6}$. A fidelidade aos fatos históricos nos remete a um ponto de convergência entre a história daquela praça e a da cidade se levarmos em conta o ano de 1917 como marco: o grande começo da exploração do carvão e a criação da Praça.

Pode-se afirmar que a história da cidade de Criciúma e a história da Praça Nereu Ramos são duas histórias que estão fundidas uma na outra. Ou seja, a história desta última se confunde com a história da própria cidade. A frase parece óbvia, mas o que se destaca aqui é o fato da íntima relação da Praça Nereu Ramos com a história de Criciúma enquanto cidade do carvão. O início da vida de Criciúma com as sucessivas vindas de colonos e o seu crescimento vertiginoso como cidade com a exploração de carvão (NASCIMENTO, 2004, p. 34) e a vida e definição da Praça Nereu Ramos como efetiva praça, acompanhando o progresso da cidade de Criciúma, são dois lados de uma mesma moeda.

A imagem de "dois lados de uma mesma moeda" não expressa, no entanto, toda a dinâmica subjacente. A praça faz parte do processo de desenvolvimento com suas idas e vindas. Ela existia, até 1930, sem o jardim e também não tinha o nome que tem hoje ${ }^{7}$. Foi somente em 1930, num período em que se assistia à grande crise econômica mundial, que a praça recebeu o seu nome atual. Foi quando também se delineou a construção de seu jardim.

\footnotetext{
5 "Aranhas" eram charretes de duas rodas, normalmente puxadas por um cavalo. Serviam como veículo de locomoção com capacidade para duas ou três pessoas. Ostentavam, normalmente, rodas altas e tinham bons molejos para abafar o impacto do atrito das rodas (Nota dos autores).

${ }^{6}$ Boldorini (2013); Histórico... (2012).

${ }^{7} \mathrm{~A}$ Praça, a partir de 1930, homenageou Nereu Ramos, na época, influente parlamentar catarinense, nascido em Lages, SC, em 1888. Foi deputado estadual e deputado federal. Fundou o Partido Liberal Catarinense - PLC e, mais tarde, foi um dos criadores do Partido Social Democrático - PSD, em Santa Catarina. Foi Governador do Estado de Santa Catarina e Senador da República. Chegou a ser Vice-Presidente da República (1946-1951) e, mais tarde (entre 1955 e 1956), assumiu como Presidente da República nos dois meses e meio entre o mandato de Café Filho e Juscelino Kubitschek.
} 
$\mathrm{Na}$ época, a imagem espacial e o modo de apropriação do local eram totalmente diferentes do que temos hoje, pois a construção do jardim e o agradável aconchego das árvores à sua volta, proporcionando conforto, sobretudo nos dias de sol e calor, contribuíram para novas leituras e formas de apropriação da praça, diferenciando-se das leituras e formas de apropriação existentes anteriormente.

As experiências de apropriação da praça eram as mais diversas possíveis, além da funcionalidade que lhe era reservada, o de acolher nas belas horas de lazer a "italianada" nos seus valentes cavalos e, mais tarde, o de servir de campo de futebol para os jovens. A Praça Nereu Ramos, na memória dos usuários, possuía uma imagem funcional comum, quer na memória do povo simples, quer na de políticos e do clero. Tanto é verdade que qualquer visita pública feita à cidade deveria passar necessariamente por esta Praça. A proximidade da estação ferroviária, que ficava a uns 200 metros do seu entorno, ${ }^{8}$ proporcionava um maior fluxo de pessoas de todas as classes, etnias e idades no local. Isso tudo está detalhado em Nascimento (2004, p. 54).

No ano de 1966, a Praça Nereu Ramos teve importante incremento de melhorias com a construção do calçamento e do chafariz. Isso também coincidiu com a inauguração da Fundação Educacional de Criciúma, a qual tinha a missão de implantar o ensino superior no município.

Segundo Valera, Iñiguez e Pol (1996, p. 45), "o espaço não tem um sentido meramente funcional, é um resumo da vida e das experiências públicas e íntimas". Assim, na geografia do local, deve ser considerado o antes e o depois das construções. Isso faz parte da identificação do espaço. Além do arranjo espacial natural, a antiga estação ferroviária, as primeiras casas comerciais, as primeiras residências e a capela não podem ficar de fora, pois são variáveis fundamentais para que se desencadeiem processos diferenciados de apropriação da praça (VIEIRA, 2010, p. 52). Além da identificação do espaço e seus diversos apelos no sentido de acolhida e proteção, vividas das mais diferentes formas, a apropriação envolve sempre, também, aspectos mais profundos, os quais devem ser buscados na percepção da poética e dos processos de identidade das pessoas. Estes últimos

\footnotetext{
${ }^{8}$ A estação ferroviária era ponto principal, e, teoricamente, todas as ruas e ruelas se cruzavam nesse ponto, o que permitia uma aglomeração constante de pessoas.
} 
podem ser visualizados tanto na sua dimensão pública quanto na sua dimensão mais privada.

É o que faz com que um simples espaço se transforme em um lugar pleno de conteúdos simbólicos. Essa passagem da "condição" de espaço para a "condição" de lugar é resultante da fecundação das funcionalidades - frias, calculadas e inóspitas - pela "habitação" do ser humano com sua poética e seus processos de identidade repletos de pulsações e de vida. A praça não é mais espaço de conveniências e funcionalidades, mas lugar de vida, de memória, de saudade e de cultivo pessoal.

Na perspectiva de Marc Augé (2005, p. 53), "o lugar é necessariamente histórico a partir do momento em que, conjugando a identidade e a relação, ele se define por uma estabilidade mínima". O longo percurso do "banhadão cortado pelo rio", dominado por cresciúmas ${ }^{9}$, até a cidade de Criciúma ${ }^{10}$ que conhecemos, com a Praça Nereu Ramos, testemunha, com certeza, muitos trânsitos de espaço para lugar, ou seja, um espaço utilizado para descanso e passagem. Aquele ambiente passou a ser habitado por significados humanos sempre mais complexos e intensos. Aliás, de Cresciúma a Criciúma, lembra o título de uma obra de Naspolini Filho (2007).

Figura 2: Capim Cresciúma.

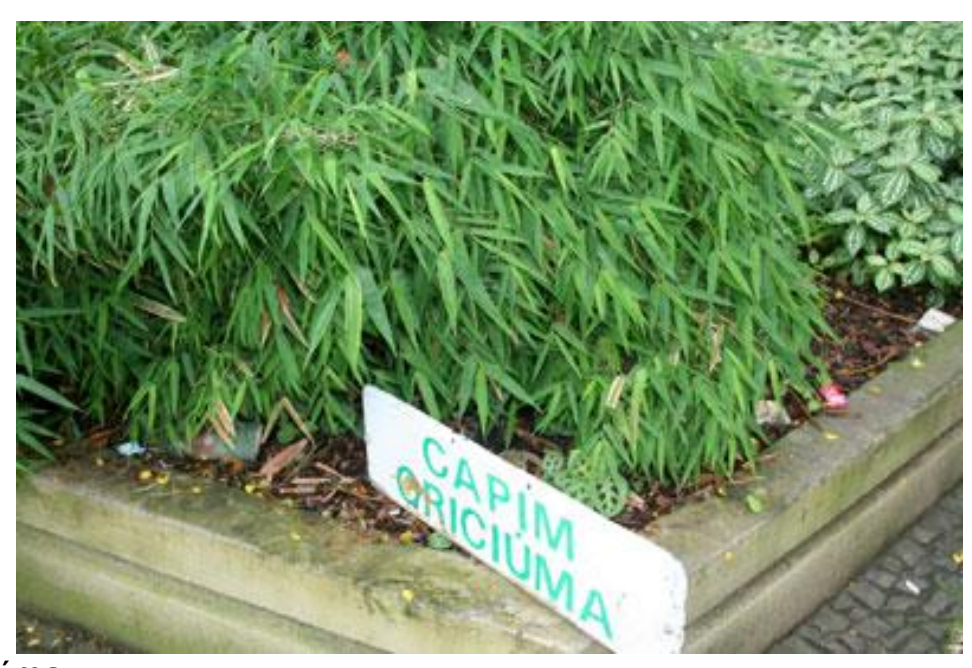

Fonte: Lima e Giustina (2013)

\footnotetext{
${ }^{9}$ Cresciúma é uma espécie de capim que crescia com fartura no local, dando origem ao nome da cidade hoje chamada de Criciúma.

${ }^{10}$ Até 1943 o nome da cidade era Cresciúma. A partir desta data "passa a ser conhecida como Criciúma, e também como sendo a Capital Brasileira do Carvão, título mantido até os dias de hoje”. (CRONOLOGIA..., 2012).
} 
As diferentes fases da Nereu Ramos testemunham um processo rico de transformações sucessivas, com idas e vindas do predomínio da ideia de um espaço para o predomínio da ideia de um lugar. Trata-se do processo histórico de constituição de um lugar antropológico, fazendo com que aquele espaço já não seja mais um espaço qualquer, facilmente substituível por outro, mas um princípio de sentido para quem nele convive ("habita") diariamente e, por consequência, também um princípio de inteligibilidade para quem tem o privilégio de observá-lo. Lembramos aqui a concepção de Augé quando se refere à constituição de um lugar antropológico na medida em que este se torna "simultaneamente princípio de sentido para aqueles que $\mathrm{o}$ habitam e princípio de inteligibilidade para quem 0 observa" (AUGÉ, 2005, p. 51).

No bojo da constituição desse lugar antropológico está todo um processo de apropriação e de pertencimento, no qual os diferentes usuários, pessoas que "habitam" de diferentes formas esse "lugar", vivem poéticas pessoais e processos de identidade próprios. Os usuários possuem representações singulares de espaços públicos. Estas se diferem umas das outras conforme o uso que se faz delas.

\section{OS USUÁRIOS (A VIDA DESSE LUGAR ANTROPOLÓGICO)}

Os taxistas, na sua rotina diária; os comerciantes ambulantes; os estudantes, em seu trajeto e convívio escolar; os funcionários, em seus horários de almoço; os transeuntes comuns; os visitantes turistas; as profissionais do sexo; as devotas e os devotos do rosário aguardando que se abra a Igreja; os casais aguardando um pelo outro; os aposentados contemplando a algazarra rítmica do vai e vem; as senhoras que, sem pressa, fazem tempo aguardando minutos, na espera do sol se abrandar, para continuar a caminhada. São diferentes formas de se fazer "habitante" desse lugar antropológico que é a praça.

A Praça Nereu Ramos cumpre uma das funções primeiras das praças públicas. Ela supera a ideia das simplesmente "belas praças" voltadas para determinadas exigências estéticas, sem envolvimento de interlocução poética com os usuários. Nela, a vida está expressa. Isso não se dá só em termos de adesão natural, mas se dá, sobretudo, enquanto atração do enigma resolvido de um espaço 
capaz de conjugar interioridade e exterioridade. Trata-se de duas dimensões que são, ao mesmo tempo, fechadas e abertas (ARANTES, 2000, p. 102).

Quem são os usuários da praça? Usamos a resposta de Vieira (2010) sobre os usuários dos espaços públicos em geral. Segundo ele, são "todas as pessoas que, de uma forma ou de outra, utilizam os espaços públicos, seja para caminhar, brincar, apreciar, ler, jogar, sentar, namorar, trabalhar, etc." (VIEIRA, 2010, p. 38). Ao falarmos da praça como lugar antropológico, repleto de subjetividades, estamos atentos às singularidades de cada usuário, em particular, e de todos os usuários, no seu conjunto.

Os usuários, a depender do seu papel em relação ao local em causa, no nosso caso a praça, são classificados em: 1) ativos: frequentadores assíduos e exploradores da praça; 2) passivos: frequentadores ocasionais, transeuntes ou visitantes esporádicos. Ou seja, há formas mais ativas e assíduas e formas mais passivas e esporádicas de se "habitar" esse lugar antropológico.

Os primeiros são os que fazem uso periódico e frequente do local para um fim específico. Na Praça Nereu Ramos, temos os aposentados, que se fazem presentes nesse local cumprindo religiosamente os encontros, com um e outro faltando, mas há, normalmente, aposentados no início do dia e no início da tarde, ou seja, por volta das 9:00 e das 14:00 horas nos dias de semana, variando em alguns horários. Esses horários são os mais concorridos pelos usuários. Também os vendedores ambulantes, o pipoqueiro, o menino do algodão doce, os ciganos, as profissionais do sexo, etc. demonstram grande assiduidade ativa na exploração da praça para finalidades pessoais específicas.

O segundo grupo de usuários não é tão ligado de forma "ativa" e frequente à praça. São mais propriamente consumidores passivos, transeuntes ou visitantes esporádicos. Trata-se dos que fazem uso da praça, porém, não direta e assiduamente, isto é, exploram o local ocasionalmente. Temos, neste sentido, aqueles que se deslocam para assistir ao filme no shopping, aguardar por um encontro para se deslocar a outro lugar, como almoçar nos restaurantes do entorno. Também há os que fazem trabalhos na praça, como é o caso dos funcionários da prefeitura, os quais trabalham na mudança da calçada. São deste grupo, também, certos transeuntes que param por alguns instantes para atender ao celular e acabam 
demorando-se aí mais tempo do que previram; os estudantes dos colégios e escolas infantis ao redor da praça; as babás que passam periodicamente para deixar ou buscar os meninos. Há, ainda, grupos de senhoras que vendem seus artesanatos e estão diariamente na praça.

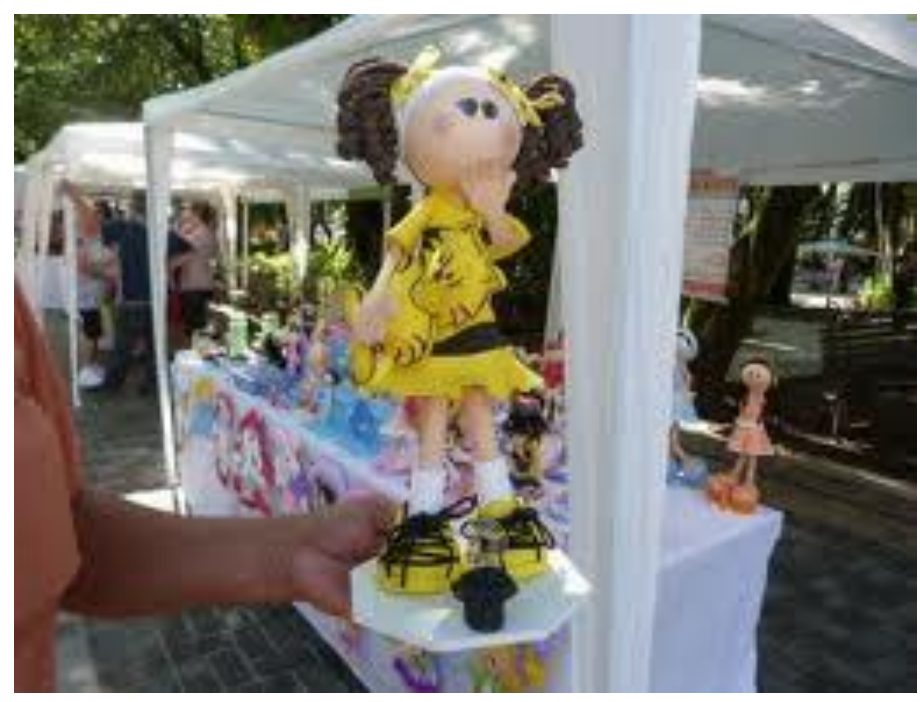

Figura 3: Artesanato na praça

Fonte: Mambo Seda (2013).

Toda classificação é empobrecedora. Assim, a simples divisão em usuários ativos e usuários passivos não retrata a realidade da população que frequenta a praça, em toda a sua diversidade, pois existem, por um lado, taxistas ocasionais ao lado de taxistas permanentes; profissionais do sexo casuais ao lado das permanentes; vendedores ambulantes, etc. Também existem, por outro lado, diferentes usuários que, mesmo sendo classificáveis entre os esporádicos e passivos, acabam fazendo da praça uma dimensão integrante de sua vida e de seu processo de identidade, devido às fruições poéticas momentâneas. Basta, por exemplo, um momento de paz e contemplação da vigorosa pujança das árvores centenárias da Nereu Ramos para se vivenciar o encanto do contraste desse oásis com a arquitetura e as métricas da vida urbana do entorno. São momentos que podem se eternizar no processo de percepção da vida urbana e de identidade de alguém. 


\section{OS PROCESSOS DE IDENTIDADE (USUÁRIOS DA PRAÇA, SUAS POÉTICAS E SEUS PROCESSOS DE IDENTIDADE)}

Trabalhar o conceito de identidade nos espaços públicos urbanos, em particular na Praça Nereu Ramos, situada em Criciúma, SC, é deveras desafiador se partirmos, sobretudo, do fato de que o conceito de identidade é, em si, um conceito "extremamente polissêmico" (FOLLMANN, 2001, p. 44).

Não se trata aqui de retomar todo um debate de revisão do conceito de identidade. Não é essa a finalidade do presente texto. Pinçamos, no entanto, algumas ideias de autores que podem nos ajudar a avançar, numa aproximação do conceito de processos de identidade dentro do contexto da vida na praça, destacando, sobretudo, a sua poética. O nosso foco está na relação entre os processos de identidade e um lugar antropológico que é a praça.

Cabe ressaltar que a nossa atenção aqui está nos usuários da praça para os quais esta tem efetivamente um significado. Pois, sabe-se que há cidadãos criciumenses os quais, no sentido de Enric Pol, nunca se apropriaram, ou seja, nunca se identificaram e deixaram que a Praça Nereu Ramos os marcasse de alguma forma. Outros criciumenses a conhecem apenas como um espaço intermediário para o centro. Em outras palavras, estes têm, normalmente, uma percepção muito superficial, mal percebendo o verde da praça, incrustrado no meio de prédios sempre mais agressivos e ruas agitadas. Chega-se ao ponto de não se poder perceber as mudanças que ocorrem no entorno dela.

No entanto, a imagem percebida da praça perdura nas mentes e corações de alguns de seus usuários. Nestes, a imagem deste ambiente tem guarida, ela "habita" neles definitivamente. Por ela ter Ihes gerado uma grande familiaridade, eles fazem uso direto da mesma. A praça acaba fazendo parte da organização de sua própria vida, ou seja, a sua imagem mental está refletida em seu processo de identidade. Isso vai muito ao encontro das contribuições de Kevin Lynch (1997) quando este fala da imagem mental. 


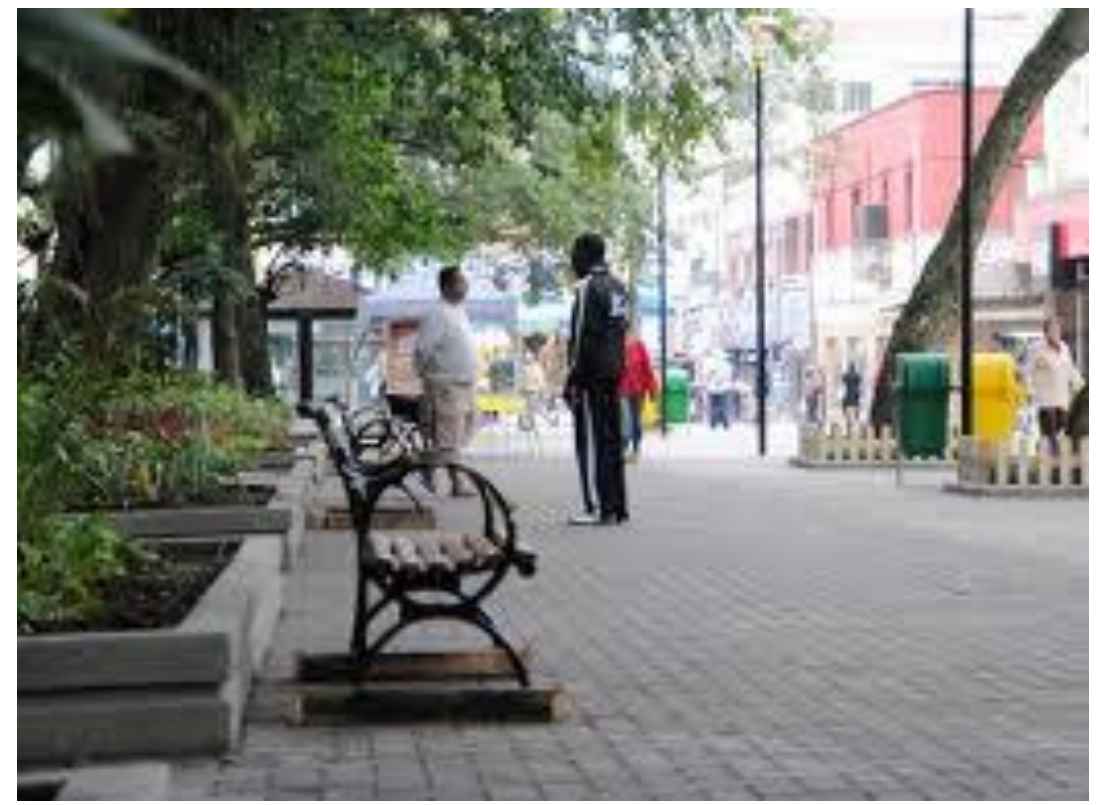

Figura 4: Amigos que se encontram na praça.

Fonte: Mambo Seda (2013).

Para referidos usuários, a Praça Nereu Ramos tornou-se efetivamente um lugar antropológico. Ela passou a habitar os seus processos de identidade como uma identidade de lugar. Os processos de identidade desses usuários estão embebidos deste lugar que é a Praça Nereu Ramos. Eles se produzem em relação com este lugar. A Praça, como lugar antropológico, para esses usuários, possui uma identidade desenvolvida pelo sentido simbólico, poético, histórico, em suma, antropológico, que o próprio sujeito estabelece com este lugar. Cada usuário constrói a relação com a Praça à sua maneira. Estamos, sobretudo, atentos aos diferentes usuários que fazem da Praça um lugar antropológico. A Praça Nereu Ramos resulta na construção de diversos lugares antropológicos para diferentes tipos de usuários, assim como também, para outros, não passa de um simples espaço sem especificidade. Podemos definir o lugar como espaço "específico, concreto, conhecido, familiar, delimitado: ponto de práticas sociais específicas que nos moldam e nos formaram, e com as quais nossas identidades estão estreitamente ligadas" (GONÇALVES, 2007, p. 58).

Nos processos de identidade, entre outras dimensões, a dimensão poética sempre representa um papel importante. Esta dimensão revela aspectos mais profundos, poucas vezes explicitados no gestual e na expressão comuns, dentro da relação dos sujeitos com o seu entorno. 
Referimos, acima, a concepção de imagem ou percepção em Kevin Lynch (1997, p. 7). Segundo este autor, a imagem é construída e desenvolvida num processo constante de interação com a informação perceptiva e filtrada na singularidade, na memória e na poética de cada sujeito. Ao falar da Praça repercutem diferentes lugares antropológicos, segundo grupos de usuários, mas ela também pode repercutir (ou reverberar) uma grande diversidade de imagens, como já sinalizamos. No entanto, é importante frisar, a imagem de uma determinada realidade ou espaço público - parque, praça -, pode variar significativamente entre os seus usuários e/ou observadores, ou seja, pode haver espaços públicos ou parques de uma determinada localidade que, ao mesmo tempo em que são familiares e aconchegantes e se apresentam plenos de significado e de fruição poética, para uns são insignificantes aos olhos de outros.

Alguns autores conceituam a identidade partindo do processo de diferenciação, ou seja, o sujeito constrói sua identidade, ou melhor, vivencia processos de identidade, na medida em que se percebe como diferente do outro, como singular. A permanência na Praça Nereu Ramos constituiu-se, de certa forma, para os pesquisadores, num laboratório neste sentido. Foram perceptíveis processos concretos e relacionais de singularização dos traços segundo diferentes grupos de usuários e segundo os processos de identidade dos sujeitos particulares.

Foram focados os processos de identidade, os quais, no caso específico deste estudo, dão-se na relação e construção do lugar antropológico que é a Praça Nereu Ramos. Nos debates sobre identidade existe, normalmente, um grande consenso em torno da ideia de que está em jogo a estruturação do sujeito como um ser único e, portanto, possuidor de uma identidade. Esta identidade construída, no entanto, não possui um fim em si, é um processo contínuo que "costura o sujeito à estrutura" (HALL, 2005, p. 12) mediante a influência das experiências, quer em nível pessoal quer em nível social. É o que preferimos denominar de processo de identidade.

No processo de identidade há duas dimensões importantes, sem as quais não se pode perceber a poética do mesmo. São as dimensões do espaço e do tempo. Segundo nos recorda Hall $(2005$, p. 71$)$, "todas as identidades estão localizadas no espaço e tempo simbólicos". 
O espaço tem condições de se tornar um lugar (antropológico) na medida em que acumula tempo de relação e convívio. Um parque, uma praça ou qualquer espaço público podem ser transformados em lugares antropológicos enquanto produtos de processos de identidade vividos pelos sujeitos que os frequentam e usam.

O espaço passa a ser simbólico quando, pelas imagens que cria no observador, faz com que seja percebido como um lugar. O resultado da observação é de fórum pessoal, ou seja, da subjetividade do observador.

As conexões no tempo com o passado, como histórico que o espaço recorda ou repõe aos usuários, é, também, muito pessoal, dependendo do modo como foram processadas as interações sujeito-meio e espaço-tempo na construção do lugar.

O espaço e o tempo podem ser recompostos de forma gostosa e harmoniosa e a praça facilmente provoca isso na experiência pessoal dos seres humanos, numa verdadeira relação estética consubstanciando em profunda fruição poética os processos de identidade dos sujeitos.

Isso faz as pessoas gostarem de estar na praça, serem assíduas ou permanentes nela ou gostarem de voltar à praça sempre que possível. $O$ pesquisador discreto e silencioso, em repetidos momentos na Praça Nereu Ramos, conseguiu registrar isso. Foi possível perceber no jeito de ser dos usuários momentos de fruição poética. O que aqui chamamos de poética é a forma de fruição harmoniosa por meio da qual o espaço e o tempo tomam conta dos sujeitos nesse lugar.

Nem todos são expostos ao impacto poético desse lugar. As percepções são diferenciadas, pois também existem aqueles que frequentam a Praça Nereu Ramos e parece que nunca conseguiram ter essa vivência, esse impacto de poética na praça. No caso, esta acaba não sendo incluída no referencial de seu processo de identidade.

Isso, no entanto, não é tudo. Os processos de identidade vivenciados pelos usuários da praça, a par dessa referência à poética, dão-se, sobretudo, como processos que envolvem uma complexidade mais densa na interação entre a dimensão coletiva e a individual. Isso foi observável nos diferentes grupos de 
usuários ativos da praça. Nos coletivos usuários sempre se destacam também os usuários individuais.

É oportuno trazer aqui a reflexão sobre os processos de identidade presente no artigo "Identidade como conceito sociológico", de Follmann (2001, p. 59). São processos que se dão na:

permanente interação entre os sujeitos, diferenciando-se e considerados diferentes uns dos outros ou assemelhando-se e considerados semelhantes uns aos outros, e carregando em si as trajetórias vividas por estes sujeitos, em nível individual e coletivo e na interação entre os dois, os motivos pelos quais eles são movidos (as suas maneiras de agir, a intensidade da adesão e o senso estratégico de que são portadores) em função de seus diferentes projetos, individuais e coletivos.

Em outro texto, Follmann (2012, p. 86) explicita ainda melhor as diferentes dinâmicas envolvidas nesta concepção, quando coloca que "[...] processos de identidade envolvem dinâmicas coletivas, dinâmicas individuais e dinâmicas que expressam interações entre o nível individual e o nível coletivo, colocando em permanente diálogo valores socialmente propostos ou disciplinados e valores pessoalmente buscados ou reivindicados".

Estes processos que sempre refletem uma "costura" - de uma parte, entre o que é "herdado" e o que é "almejado" e, de outra parte, entre o que é "atribuído" e o que é "assumido" - são processos que acontecem nas diferentes esferas de sociabilidade ou dimensões da vida social; são processos que ocorrem, em alguns aspectos, com intensidade especial na vida da Praça. São, certamente, processos perceptíveis, de uma forma ou de outra, em todas as praças e espaços públicos. A nossa atenção foi com relação aos usuários que "habitam" a Praça Nereu Ramos, ou seja, os taxistas desta Praça, as profissionais do sexo, os idosos, as mulheres frequentadoras da igreja no local, etc.

Diferentes indivíduos ou grupos que "habitam" o mesmo lugar antropológico - que é a Praça Nereu Ramos -, nesse caso, movem-se segundo seus processos de identidade, os quais são muito diversos. Deveríamos começar pela distinção entre os que verdadeiramente "habitam" e os que não chegam a "habitá-la". A nossa atenção aqui, no entanto, está voltada aos usuários da praça, aos "habitantes" deste lugar antropológico. 
Trata-se de lugar, sobretudo, de interação humana. Talvez seja interessante trazer para esta reflexão também uma contribuição de Darmegian, o qual muito nos inspira. Reproduzindo suas palavras, estamos na presença de um fenômeno que resulta da "[...] interação verdadeiramente humana que deve se caracterizar pela representação do outro dentro de nós, sem nos confundirmos com ele; dar a ele um lugar no sistema simbólico, aceitá-lo como diferente enquanto ser desejante mas, igual enquanto direito ao desejo, reconhencendo-o sujeito de sua própria história". (DARMEGIAN, 2001, p. 89).

Fixemos a nossa atenção no grupo de idosos como um dos grupos usuários ativos que "habitam" este lugar antropológico, despertando muito a atenção do observador. Como já foi pontuado, há dois momentos no dia em que afluem com mais frequência e maior intensidade: em torno das 09:00 e em torno das 14:00 horas. Alguns conversam. Outros se sentam solitários curtindo o ambiente gostoso da sombra, observando os transeuntes e esperando a atenção de alguém. A praça é uma espécie de extensão da própria casa, ou melhor, apartamento. É, de certa forma, uma segunda habitação. É como se fosse o quintal da própria moradia, um quintal não escondido, mas público, que favorece a interação e o contato humano. Os momentos recorrentes de presença do idoso na praça são certamente momentos de maior definição e intensificação dos seus processos de identidade. 
FRANCISCO,T.M.S.; FOLLMANN, J.I.; GIOVANNI, E.N.; GONÇALVES, T.M.

A Praça, a Poética e os Processos de Identidade: desvelando aspectos da identidade urbana

Quadro 1 - Quadro dos grupos temáticos.

\begin{tabular}{|c|c|c|c|c|c|c|c|}
\hline Grupos & Aposentados & Artistas & Ativistas & $\begin{array}{c}\text { Profissionais do } \\
\text { sexo }\end{array}$ & Taxistas & Transeuntes & $\begin{array}{l}\text { Vendedores } \\
\text { Ambulantes }\end{array}$ \\
\hline Temas & Memória & Diversão & $\begin{array}{l}\text { Compromisso } \\
\text { Social }\end{array}$ & Sexo & Solidariedade & Lazer & Comércio \\
\hline Objetivos & $\begin{array}{c}\text { Reencontro com } \\
\text { amigos e ex-colegas. } \\
\text { "Sentir" a vida. }\end{array}$ & $\begin{array}{l}\text { Fazer as } \\
\text { pessoas } \\
\text { sorrirem de } \\
\text { forma } \\
\text { simples e } \\
\text { culta. }\end{array}$ & $\begin{array}{l}\text { Convite para } \\
\text { participação em } \\
\text { eventos. } \\
\text { Compras de } \\
\text { produtos. }\end{array}$ & Adquirir dinheiro. & $\begin{array}{l}\text { Levar o cliente } \\
\text { ao seu destino e } \\
\text { ganhar alguns } \\
\text { trocados. }\end{array}$ & $\begin{array}{c}\text { Diversos: leitura, } \\
\text { descanso. }\end{array}$ & $\begin{array}{c}\text { Vender suas } \\
\text { peças. }\end{array}$ \\
\hline $\begin{array}{l}\text { Fenômeno } \\
\text { observado }\end{array}$ & $\begin{array}{c}\text { Idosos conversando } \\
\text { ou lendo jornal entre } \\
10 \mathrm{~h} 00 \text { da manhã e } \\
13 \mathrm{~h} 00 .\end{array}$ & $\begin{array}{c}\text { Palhaços } \\
\text { contando } \\
\text { estórias, } \\
\text { alguns } \\
\text { músicos, } \\
\text { ilusionistas e } \\
\text { orquestra } \\
\text { sinfônica. }\end{array}$ & $\begin{array}{l}\text { Feira de livros, } \\
\text { campanhas de } \\
\text { saúde e } \\
\text { programas } \\
\text { religiosos. } \\
\text { Exposição } \\
\text { fotográfica. } \\
\text { Convite à } \\
\text { manifestação. }\end{array}$ & $\begin{array}{c}\text { Jovens mulheres } \\
\text { entre } 24 \text { a } 40 \text { anos } \\
\text { interpelando } \\
\text { aposentados e } \\
\text { transeuntes para } \\
\text { atividade sexual. }\end{array}$ & $\begin{array}{c}\text { Organização e } \\
\text { partilha de } \\
\text { instrumentos e } \\
\text { peças de carro } \\
\text { para conserto. } \\
\text { Conversas } \\
\text { prolongadas e } \\
\text { carregadas de } \\
\text { emoção. } \\
\text { Disposição em } \\
\text { dar informação. }\end{array}$ & $\begin{array}{l}\text { Passeio familiar; } \\
\text { encontro amoroso; } \\
\text { funcionário } \\
\text { aguardando seu } \\
\text { turno chegar; } \\
\text { estudantes } \\
\text { conversando; grupos } \\
\text { de jovens apenas } \\
\text { observando a praça. }\end{array}$ & $\begin{array}{c}\text { Gente humilde } \\
\text { caminhando de um } \\
\text { lado ao outro com } \\
\text { diversas peças } \\
\text { para vendê-las. }\end{array}$ \\
\hline
\end{tabular}

Fonte: Mambo Seda e Gonçalves (2013) 


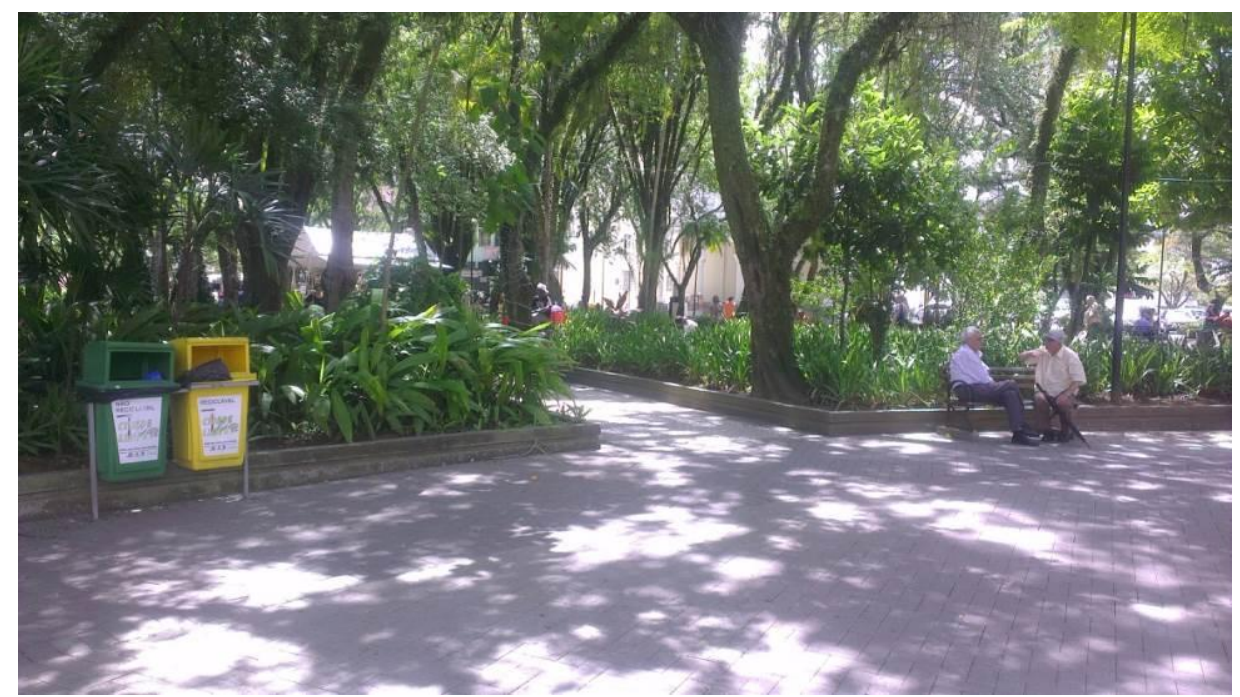

Figura 5: Aposentados conversando na Praça.

Fonte: Mambo Seda (2013)

Atenção também deve ser dada às profissionais do sexo, que aparecem com frequência quase regular na praça. Estas, frequentemente, abordam o grupo de idosos, sobretudo nos horários aqui mencionados e acabam fazendo parte da paisagem, bem no coração da praça, identificando-se com o lugar. Os motivos podem ser os mais diversos, desde o fato de sua "clientela" alvo se localizar nesse lugar; o fato desse lugar, de certa maneira, passar despercebido aos olhos de muitos transeuntes quanto à prática dessa atividade, quer ainda pelo fato da exposição da qual são poupadas pelas caraterísticas do lugar, como a existência de uma igreja, o centro do comércio, o movimento. Isso fica evidenciado, sobretudo, quando essa atividade é diurna. A praça assume uma função protetora de sua atividade.

Existe também o grupo dos taxistas, como já mencionado, que se constitui num coletivo interessante entre os que "habitam" esse lugar antropológico de forma ativa, ou seja, entre os usuários ativos. Porém essa experiência coletiva ou esse coletivo se afirma juntamente com o desenvolvimento da imagem singular em cada um dos taxistas, obedecendo ao processo histórico experiencial que foi constituindo a sua personalidade. São os taxistas da praça. Existem singularidades em cada sujeito, as quais o coletivo não rompe.

Não se trata, portanto, de um simples ponto de táxi. Apesar de suas singularidades, trajetórias pessoais, motivações, jeitos de ser e fazer, os taxistas da 
praça têm em comum algo de muito profundo: a praça e o gosto de nela estar e fazer nela o seu ponto. A particularidade como o taxista se identifica com o lugar, ao mesmo tempo em que este o diferencia dos outros taxistas de outros pontos de táxis, também o define. Existe toda uma ritualística nesse grupo, envolvendo, em geral, cuidados com os carros, verificando o funcionamento mecânico de diferentes partes do motor, em que todos opinam e se aconselham mutuamente, revezando-se isto com rodas de conversa e descanso à sombra gostosa deste ponto de trabalho que é a praça. São motoristas de praça. Aliás, não é por acaso que as expressões "motorista de praça" e "carro de praça" são traduções de taxista e de táxi. Assim, os motoristas da praça são duplamente da praça: por um lado, eles a "habitam" como lugar antropológico e, por outro, a utilizam como local de trabalho. Nos dois sentidos, a praça acaba "habitando" neles e em seus processos de identidade.

Além dessas três descrições de usuários típicos, duas observações a mais são fundamentais para ilustrar este item: a primeira é feita a partir dos encantamentos do fotógrafo turista transeunte e a outra é feita a partir do olhar das senhoras e dos senhores devotos que esperam se abrirem as portas da igreja.

O fotógrafo que aos finais de semana se apaixona pela praça e seus contornos, pelo modo como as árvores se entrelaçam umas nas outras bem no "coração" da praça; como as folhas exuberantes e verdes se afagam mutuamente e tecem uma refrescante proteção para os usuários, formando uma cobertura verdejante cheia de vida e poesia, que além de proteger dos raios do sol descansa os olhos e eleva a alma. O que o fotógrafo transeunte intui e vivencia de forma, talvez, fugidia, é, com certeza, a vivência muitas vezes repetida, mas sem registro dos mais diferentes usuários. É a poética que acontece na mútua relação entre "habitante" e "habitado" que faz com que a permanência fiel esteja garantida. Foram observadas, neste sentido, diversas pessoas que simplesmente chegam e ficam paradas olhando todos os contornos da praça ou, então, se sentam de forma descansada, com ar de contemplação ou, simplesmente, de curtição ou fruição do ambiente. Às vezes, tratam-se de paradas, simplesmente, por um impulso momentâneo, por algo diferente que está acontecendo ou que causa intriga ou curiosidade no transeunte. 
O olhar das senhoras e dos senhores devotos que esperam a chegada de outras e outros ou a abertura das portas da igreja estão muitas vezes repletos de curiosidades, interrogações e sustos. O mesmo olhar estupefato dessas pessoas frente ao outro, ao diverso que se apresenta ou transita na praça, que se repete quase cotidianamente, simboliza e sintetiza também, de certa forma, os múltiplos olhares que se cruzam no convívio da praça, entre os diferentes indivíduos ou grupos de usuários. A praça é o encontro e o convívio do diferente e, muitas vezes, do oposto. Enquanto tal, nós podemos considerá-la uma incubadora fecunda de processos de identidade. O convívio entre processos de identidade profundamente diferentes como são os dos taxistas, das profissionais do sexo, dos idosos, das devotas e devotos da igreja é, por si só, um grande laboratório.

Estes são alguns exemplos pontuais que nos mostram como a Praça Nereu Ramos, por meio dos seus usuários, ou seja, por meio dos que nela "habitam" e se deixam "habitar" por ela, pode contribuir para ampliarmos o entendimento dos processos urbanos de identidade ou, abreviando, para o estudo das identidades urbanas.

\section{BREVES COMENTÁRIOS CONCLUSIVOS}

As múltiplas idas e vindas e as recorrentes "permanências" de uma grande diversidade de usuários carregam em si, na maioria dos casos, um estreitamento contínuo e crescente dos mesmos usuários com este lugar antropológico e dos usuários entre si.

A Praça Nereu Ramos é muito mais do que a praça. Ela torna-se parte dos seus usuários, impregnando os seus processos de identidade. Tudo o que esboçamos e registramos neste artigo contém uma dupla percepção ou um duplo sentido. Ao mesmo tempo em que estão postos em pauta, por um lado, os processos de identidade dos usuários envolvendo as suas respectivas atividades ou não atividades - na praça, e, por outro lado, a própria praça com sua vida, sua expressão e sua finalidade.

O duplo sentido caracterizante das identidades quer dos sujeitos quer do lugar, enquadra-se num único fenômeno de singularização, definido no lugar 
antropológico que é a Praça Nereu Ramos enquanto lugar que expressa uma relação fecunda entre "habitante" e "habitado".

As contribuições de Damergian (2001) em muito nos iluminaram também nesta nossa incursão na praça. A partir de suas contribuições, fica patente para nós de que estamos falando de um fenômeno em que se processa um encontro entre as individualidades dos sujeitos e os objetos socializantes sintetizados pela praça, no seu contexto e em seus usuários.

Sabemos que os processos urbanos de identidade dizem respeito à construção da identidade no âmbito do cotidiano da vida urbana. Portanto, não podemos deixar de considerar, no processo de construção da identidade, as relações que as pessoas mantêm levando-se em consideração o espaço e os lugares criados por elas dentro deste espaço. Na elaboração do texto, concentramos a nossa atenção na gestação e na vida do lugar antropológico chamado Praça Nereu Ramos, dentro do espaço criciumense. Mesmo que não se tenha avançado muito mais do que estabelecer um diálogo entre as reflexões dos autores e as observações empíricas nessa praça, o texto trouxe contribuições fecundas para que se avance na discussão dos processos urbanos de identidade.

Trata-se de um esforço por arrolar novos elementos e aportes nas reflexões sobre o conceito de "identidade de lugar", já amplamente referido e desenvolvido por Tuan (1983), Gonçalves (2004), Arcaro e Gonçalves (2012), fazendo-o dialogar com os processos urbanos de identidade.

Também nos remete aos aportes de Harvey (2006), quando este nos aponta a perspectivada possibilidade dos espaços de esperança construídos por lugares onde o sujeito significa e dá sentido à vida coletiva nas configurações espaciais da praça entendida como espaço público. Lugar do encontro do eu e do outro, lugar da revelação da identidade cultural urbana forjada na diferença de múltiplos atores sociais que coabitam este espaço e constroem ali, por meio da dimensão simbólica, seus múltiplos lugares.

Como se propôs inicialmente, o artigo pretendeu aportar contribuições e interrogações para o avanço da discussão tanto do conceito de identidade urbana ou de processos urbanos de identidade como do conceito de identidade de lugar. Tanto um quanto o outro, como foi também referido, são conceitos considerados 
fundamentais dentro da proposta do Grupo Interdisciplinar e Interinstitucional de Estudos e Pesquisas sobre Meio Ambiente e Espaço Urbano - Gipmaur.

\section{REFERÊNCIAS}

ARANTES, O. O Planejamento Estratégico de Belo Horizonte: planejado por quem e para quem. Disponível em: http://wp.me/pO6H0-7t Acesso em: 16 nov. 2012.

ARCARO, R.; GONÇALVES, T.M. Identidade de lugar: um estudo sobre um grupo de moradores atingidos por barragens no município de Timbé do Sul, Santa Catarina. RA'EGA, v. 25, p. 38-63, 2012.

AUGÉ, M. Não Lugares: Introdução a uma antropologia da supermodernidade. 5.ed. Campinas SP: Papirus, 2005.

BONECAS MADE IN CRICIÚMA. Disponível em:

http://arquivo.clicatribuna.com/noticia/bonecas-made-in-criciuma-78814 Acesso em: 08 dez 2013.

BOLDORINI, M.G. A cidade de Criciúma. Disponível em:

http://www.sctur.com.br/criciuma/. Acesso em: 04 nov. 2013.

CRICIÚMA. Disponível em: http://pt.wikipedia.org/wiki/Crici\%C3\%BAma Acesso em 16 nov. 2012.

CRONOLOGIA HISTÓRICA CRICIUMENSE. Disponível em: http://camara.virtualiza.net/historia_criciuma_cronologia.php Acesso em: 16 nov. 2012.

DAMERGIAN, S. A construção da subjetividade na metrópole paulistana: desafio da contemporaneidade. In: TASSARA, E. T. de O. (Org.). Panoramas interdisciplinares para uma psicologia ambiental do urbano. São Paulo: Educ/Fapesp, 2001.

FOLLMANN, J.I. Identidade como conceito sociológico. Ciências Sociais Unisinos, São Leopoldo, v. 37, n. 158, p. 43-66, 2001.

FOLLMANN, J.I. Processos de identidade versus processos de alienação: algumas interrogações. Revista Identidade, São Leopoldo, v. 17, n. 1, p. 83-90, 2012.

GIL, A.C. Métodos e Técnicas de Pesquisa Social. São Paulo: Atlas, 1989. 
GONÇALVES, T.M. A observação Sistemática como Técnica de Percepção: a técnica do GAMOC. Criciúma, SC: UNESC, 2004.

GONÇALVES, T.M. Cidade e Poética. ljuí, RS: Unijuí, 204 p. 2007.

HALL, S. A Identidade Cultural na Pós Modernidade. 10.ed. Rio de Janeiro: DP\&A, 2005.

HARVEY, D. Espaços de Esperança. 2.ed. São Paulo: Loyola, 2006.

HISTÓRICO do carvão em SC. Disponível em:

http://www.satc.edu.br/siecesc/historico.asp Acesso em 16 nov. 2012.

LADIWG, N.I. Sem título. 2013. 1 fotografia.

LIMA, L.; GIUSTINA, K.D. Capim Criciúma. In: BOLDORINI, Marília G. A cidade de Criciúma. Disponível em: http://www.sctur.com.br/criciuma/. Acesso em: 04 nov. 2013.

LYNCH, K. A Imagem da Cidade. São Paulo: Martins Fontes, 1997.

MAMBO SEDA, T. Aposentados conversando na Praça. 2013. 1 fotografia.

MAMBO SEDA, T.; GONÇALVES, T.M. Quadro dos grupos temáticos. Criciúma: UNESC, 2013.

NASCIMENTO, D. As curvas do Trem: a presença da estrada de ferro no sul de Santa Catarina (1880-1975). Cidade, modernidade e vida urbana. Criciúma, SC: UNESC, 2004.

NASPOLINI FILHO, A. De Cresciúma a Criciúma: 1880-1960. Criciúma, SC: Ed. do autor, 2007.

NASPOLINI FILHO, A. De Marcos Rovaris a Anderlei Antoneli: os homens que governaram Criciúma. Criciúma, SC: Ed. do autor, 2005.

PRAÇA NEREU RAMOS GANHA NOVOS BANCOS. Disponível em: http://www.criciuma.sc.gov.br/site/noticia/praca_nereu_ramos_ganha_novos_bancos -7539. Acesso em: 08 dez 2013.

TUAN, Y.F. Espaço e Lugar: a perspectiva da experiência. São Paulo: Difel, 1983. 
A Praça, a Poética e os Processos de Identidade: desvelando aspectos da identidade urbana

VALERA, S. Psicologia ambiental: Bases teóricas y epistemológicas. In: VALERA, S.; IÑIGUEZ, L.; POL, E. Monografies psico-socio-ambientales. Barcelona: Universitat de Barcelona, p. 1-14, 1996.

VIEIRA, I.M. Configuração e Apropriação do Espaço Público. Estudos de suas praças em Criciúma. 2010. 108f. Dissertação (Programa de Pós-Graduação em Urbanismo, História e Arquitetura da Cidade - Mestrado) - Universidade Federal de Santa Catarina, Florianópolis. 